\title{
Verificação da estrutura fatorial, invariância e diferenças da escala de autoeficácia
}

\section{parental em pais separados}

Verification of the factorial structure, invariance, and differences in the parental self-efficacy scale

in separated parents

Verificación de la estructura factorial, invariancia y diferencias de la escala de autoeficacia

parental en padres separados

Recebido: 08/03/2021 | Revisado: 14/03/2021 | Aceito: 30/03/2021 | Publicado: 06/04/2021

\author{
Dayan M. S. Cotrim \\ ORCID: https://orcid.org/0000-0003-1834-7718 \\ Universidade de Ciências Empresariais e Sociais, Argentina \\ E-mail: dayancotrim1@ hotmail.com \\ Nilton Soares Formiga \\ ORCID: https://orcid.org/0000-0003-4907-9736 \\ Universidade Potiguar, Brasil \\ E-mail: nsformiga@yahoo.com
}

\begin{abstract}
Resumo
O impacto socioemocional na separação de um casal também é vivido por seus filhos, os quais, muitos deles desenvolvem uma grande dependência por causa da separação. Na pesquisa para com esse público, faltam instrumentos de medidas psicométricas para avaliação de construtos de pais separados em relação a seus filhos, para que profissionais da área possam utilizar. Neste artigo, pretende-se verificar a qualidade da estrutura fatorial, invariância e diferenças em pais separados do construto da autoeficácia parental. A amostra foi de 200 sujeitos, sendo 107 mães e 93 pais, com idades de 21 a 40 anos; todos estavam divorciados e/ou separados e tinham filhos com idades entre 0 e 3 anos. Todos residentes no Estado da Bahia. Os participantes responderam a questões da escala de autoeficácia parental. Realizou-se estatísticas descritivas e inferenciais e análise confirmatória. Observou-se que tanto na análise discriminativa, quanto de representatividade de conteúdo, todos os itens foram significativos, confirmando a relação conteúdo-domínio teórico da escala. $\mathrm{Na}$ análise fatorial confirmatória, os indicadores psicométricos estiveram no parâmetro estatístico que indica a qualidade da estrutura fatorial da escala e os seus índices de fidedignidade revelaram a consistência da organização fatorial, com sete fatores, interrelacionados. A dimensão Ensino e Responsividade Empática tiveram maiores escores. Os resultados revelaram que a Mãe apresentou escores mais altos comparados ao Pai. De forma geral, destaca-se que a escala de autoeficácia é consistente numa amostra de pais separados. Conclui-se que a escala de autoeficácia parental pode ser administrada em pais e mães separados na pretensão de uma orientação com uma melhor organização emocional para com os seus filhos.
\end{abstract}

Palavras-chave: Autoeficácia parental; Pais e mães separados; Escala de autoeficácia parental.

\begin{abstract}
The socioemotional impact on the separation of a couple is also experienced by their children, who, many of them develop a great dependence because of the separation. In researching this audience, psychometric measurement instruments are lacking to assess constructs of parents separated from their children, so that professionals in the field can use. In this article, we intend to verify the quality of the factorial structure, invariance and differences in parents separated from the construct of parental self-efficacy. The sample consisted of 200 subjects, being 107 mothers and 93 fathers, aged 21 to 40 years; all were divorced and / or separated and had children aged 0 to 3 years. All residents of the State of Bahia. Participants answered questions on the parental self-efficacy scale. Descriptive and inferential statistics and confirmatory analysis were performed. It was observed that in the discriminative analysis, as in content representativeness, all items were significant, confirming the theoretical content-domain relationship of the scale. In the confirmatory factor analysis, the psychometric indicators were in the statistical parameter that indicates the quality of the scale's factorial structure and its reliability indices revealed the consistency of the factorial organization, with seven factors, interrelated. The Teaching and Empathic Responsiveness dimension had the highest scores. The results revealed that the Mother had higher scores compared to the Father. In general, it is noteworthy that the self-efficacy scale is consistent in a sample of separate parents. It is concluded that the parental self-efficacy scale can be administered to separate mothers and fathers to seek guidance with a better emotional organization towards their children.
\end{abstract}


Keywords: Parental self-efficacy; Separate fathers and mothers; Parental self-efficacy scale.

\section{Resumen}

El impacto socioemocional de la separación de una pareja también la sufren sus hijos, muchos de los cuales desarrollan una gran dependencia a causa de dicha separación. En la investigación dirigida a este público, hay carencia de instrumentos de medición psicométrica para evaluar los constructos de los padres separados en relación a sus hijos, para que los profesionales del área puedan utilizarlos. En este artículo, pretendemos verificar la calidad de la estructura factorial, la invariancia y las diferencias en padres separados del constructo de autoeficacia parental. La muestra fue de 200 sujetos, 107 madres y 93 padres, con edades comprendidas entre los 21 y los 40 años; todos estaban divorciados y/o separados y tenían hijos de 0 a 3 años. Todos eran residentes del Estado de Bahía. Los participantes respondieron las preguntas de la escala de autoeficacia de los padres. Se realizaron estadísticas descriptivas e inferenciales además de análisis confirmatorios. Se observó que tanto en el análisis discriminatorio como en el de representatividad del contenido, todos los ítems eran significativos, confirmando la relación contenido/dominio teórico de la escala. En el análisis factorial confirmatorio, los indicadores psicométricos estaban en el parámetro estadístico que indica la calidad de la estructura factorial de la escala y sus índices de fiabilidad revelaron la consistencia de la organización factorial, con siete factores, interrelacionados. Las dimensiones Enseñanza y Receptividad Empática, obtuvieron puntuaciones mayores. Los resultados revelaron que la madre tenía puntuaciones más altas comparadas con el padre. En general, la escala de autoeficacia es consistente en una muestra de padres separados. Se concluye que la escala de autoeficacia parental puede ser administrada entre padres y madres separadas en la pretensión de orientación con mejor organización emocional hacia sus hijos.

Palabras clave: Autoeficacia parental; Padres y madres separadas; Escala de autoeficacia parental.

\section{Introdução}

Marcondes, Trierweiler e Cruz (2006) apontam que por diversos motivos ocorre a separação de um casal, mas o maior deles ainda é a indiferença com que um trata o outro. Cônjuges que sofrem esta experiência de terem seus laços afetivos rompidos, podem vivenciar um transtorno emocional (especialmente, estado depressivo), que capaz de experienciar por um bom tempo em sua vida. Um fato que merece muita atenção é que tal situação não se restringe apenas ao casal, mas aos filhos que fazem parte de suas vidas. Eles podem crescer num ambiente hostil ou não saber lidar de forma saudável por não terem tido suas emoções validadas nessa nova realidade (Schabbel, 2005; Marcondes, Trierweiler, \& Cruz, 2006).

Por esse motivo, acredita-se que a separação seria uma nova oportunidade para os pais e, também, para os filhos, administrarem de forma consciente a autenticidade com os seus sentimentos e comportamentos. Mas no que se refere às causas psicossociais, verificam-se conflitos que têm levado ao fim do laço conjugal, destacando-se a influência da família de origem e do meio social sobre as pessoas que vivenciam o processo de separação (Teyber, \& Hoffman, 1987; Maldonado, 1987; Jablonski, 1991; Kaslow, \& Schwartz, 1995; Almeida, Peres, Garcia, \& Pellizzar, 2000; Zordan, 2010).

Féres-Carneiro (2003) afirma que há casos em que a separação significa uma melhor qualidade de vida, condição que não exclui o processo doloroso. Após a separação, quando esta ocorre num contexto menos litigioso possível, a parentalidade passa a ser a função mais importante desempenhada pelo pai ou pela mãe, sendo um desafio que, na situação que se encontram, exigirá muito do casal separado, devido às responsabilidades que envolvem o intelecto e as demandas físicas e emocionais.

Desta maneira, a partir desse novo estilo de vida que passam a experienciar, pai e mãe deverão colocar em prática uma atitude com o foco na formação educacional e social dos filhos, associado a um bom desempenho de papéis na interação com eles, mas tudo isso dependerá da frequência e intensidade que cada um deles percebe a organização e funcionalidade da sua autoeficácia (Nunes, 2008; Meunier \& Roskam, 2009; Barros \& Batista-dos-Santos, 2010; Meneses, \& Abad, 2010; Rodriguez-Villamizar, Laura \& Amaya-Castellanos, 2019; Albanese, Russo \& Geller, 2019).

De forma geral, a autoeficácia é concebida como a compreensão que o indivíduo tem a respeito da sua capacidade de organizar e desempenhar condutas necessárias para alcançar suas metas e objetivos. Este construto afeta diretamente o comportamento das pessoas, já que aquelas com maior autoeficácia têm maior probabilidade de persistir diante de tarefas difíceis (Bandura, 1997), 
Com isso, a autoeficácia aplicada à parentalidade percebida tem revelado relação com as habilidades que o sujeito adquiriu ao longo da vida, contribuindo para avaliar o quanto as pessoas são capazes de estruturar e organizar suas atitudes frente à tomada de decisão relativa a si mesmo ou ao social (Batista, Alves e Santos, 2008; Kim, \& Ciccetti, 2003; Oliveira, 2016, Kabiyea \& Manor-Binyamini, 2019; Benatov, 2019).

Para Pajares (2002), as pessoas não apenas vivenciam o resultado dos seus esforços, mas também observam outros em situações similares e, de tempos em tempos, recebem avaliações sociais sobre a adequação da sua performance. Com isso, ao considerar que essas influências se afetam entre si, o poder de um dado modo de influência poderá ser alterado por outro, dependendo da força das outras fontes.

Sendo assim, o autor afirma que a percepção de autoeficácia é possível de ser avaliada a partir de quatro fontes, as quais seriam interdependentes, sendo elas: 1- a fonte da experiência pessoal, que é obtida por meio da interpretação de experiências prévias; 2- fonte da aprendizagem vicária, que gera a percepção de eficácia por meio da observação de outras pessoas realizando ações desafiadoras; 3 - fonte da persuasão verbal, diz respeito às persuasões sociais recebidas, que servem como meio adicional de fortalecer as crenças das pessoas de que elas possuem as capacidades para atingir o que buscam, por fim, 4- fonte que aponta os indicadores fisiológicos, esta atua quando as pessoas avaliam sua confiança para realizar certas ações pelo seu estado emocional ao executar determinadas tarefas (Pajares, 2002; Lent \& Brown, 2006; Nunes, 2008).

Assim, generalizações sobre o poder relativo dos diferentes modos de influência de eficácia devem ser qualificadas pelo balanço das forças que interagem (Bandura, Azzi \& Polydoro, 2008).

A partir dos conceitos de Bandura sobre autoeficácia, desenvolveram-se inúmeras escalas, cada uma delas para determinada população que se desejava analisar (Gouvêa, 2003; Nunes, 2008; Machado, Paes, Berbtz, \& Stefanello, 2014).

Considerando tal construto e sua respectiva definição, em verificação a base de dados de produções científicas, observaram-se a existência de escalas de avaliação da autoeficácia para outros contextos e fenômenos por exemplo: estudo relacionado ao manejo da dor crônica (Salvetti, 2004) ou ainda na autoeficácia relacionada às habilidades para a transição da faculdade para o mercado de trabalho (Vieira, Soares, \& Polydoro, 2006), para os professores (Murgo, \& Soares 2019), para os atletas (Kyrillos, 2006; Frischknecht, 2018), nas atividades físicas comuns (Selau, Espinosa, Araujo, \& Veit, 2019), em bailarinos (Silva, Luz, Afonso, Araújo, Bittencourt, Carvalho, \& Enumo, 2015), mães e gestantes hospitalizadas (Tristão, Neiva, Barnes, \& Adamson-Macedo, 2015), entre outros, mas não especificamente, para pais separados.

Dado isso, o interesse nesta temática, se deve ao fato de que, com o aumento do percentual de casais separados, chegando a $262 \%$ de separações nas últimas três décadas (IBEDFAM, 2018), bem como, devido às facilidades quanto ao processo jurídico que envolve o divórcio, também, o impacto social causado pela tomada de decisão dos cônjuges em relação a criação de seus filhos tem influenciado nas crenças de autoeficácia, - compreendida como a capacidade para realizar tarefas parentais.

Elas têm sua importância na avaliação psicológica porque existe um sofrimento psíquico que envolve os cônjuges e sua dificuldade em gerir a formação educativa dos filhos, no desenvolvimento físico, psíquico, social e existencial de cada um deles para um melhor relacionamento entre pais e filhos, após a separação. Contudo, ao considerar a constante demanda a respeito de casais separados frente a parentalidade, é fundamental que se avance no sentido de disponibilizar outros instrumentos com parâmetros psicométricos adequados, como a Escala de Autoeficácia Parental por exemplo, buscando contemplar as diferentes abordagens utilizadas por psicólogos e educadores e as demandas dos pais que procuram tais profissionais.

Diante do vazio na literatura pesquisada nas bases de dados científicas a respeito de instrumentos que possam ajudar profissionais a lidarem com o público de pais separados, no contexto da criação de seus filhos, é que o presente artigo tem, 
portanto, o objetivo de verificar a estrutura fatorial e a invariância da Escala de Autoeficácia Parental (EAP) em pais separados e, ainda, se há diferenças por conta do sexo.

\section{Metodologia}

\section{Amostra}

Trata-se de um estudo descritivo, exploratório e correlacional, de abordagem quantitativa, envolvendo pais separados residentes no Estado da Bahia. Para isso, utilizou-se à abordagem não probabilística, associada ao método bola de neve, fazendo-se necessário avaliar o ' $n$ ' amostral mais adequado para a realização do estudo.

De acordo Shaughnessy, Zechmeister e Zechmeister (2012), um estudo com abordagem quantitativa dos dados faz uso de estatísticas descritivas, como contagens de frequência, média e desvio padrão, com o objetivo de proporcionar uma síntese numérica, ou quantitativa, das observações realizadas e o tipo de estudo descritivo é usado para sintetizar dados observacionais através de escalas que podem medir e registrar os dados.

Para Creswell (2016), no estudo quantitativo, o pesquisador deve utilizar a teoria dedutivamente e a colocar no início da proposta de um estudo, na intenção de testar ou verificar a teoria, coletar os dados e fazer uma discussão sobre os resultados alcançados.

Para análise, utilizou-se o pacote estatístico G Power 3.2; software destinado ao cálculo do poder estatístico (isto é, o teste de hipótese) amostral, que avalia tanto o 'n' necessário para a pesquisa e qual o tipo de cálculo a ser realizado no estudo, a fim de garantir uma amostra adequada (Faul, Erdfelder, Lang, \& Buchner, 2007).

Para a coleta de dados, foi considerada uma probabilidade de $95 \%(\mathrm{p}<0,05)$, magnitude do efeito amostral $(\mathrm{r} \geq 0,30) \mathrm{e}$ um padrão de poder hipotético $(\pi \geq 0,80)$ para amostra total e a especificidade amostral.

A amostra foi constituída de 200 participantes, todos estavam divorciados/separados e tinham filhos com idades de 0 a 3 anos, dos quais, 107 eram mães e 93 pais, com idades entre 21 e 40 anos, residentes no estado da Bahia. Revelou-se o seguinte critério estatístico: amostra total ( $\mathrm{t} \geq 1,98 ; \pi \geq 0,98 ; \mathrm{p}<0,05$ ), amostra 1 (amostra de mães) [t $\geq 1,98 ; \pi \geq 0,95 ; \mathrm{p}<$ $0,05]$ e amostra 2 (amostra de pais) [ $\mathrm{t} \geq 1,93 ; \pi \geq 0,94 \mathrm{p}<0,05]$. Estes indicadores estatísticos, não apenas garantiram que a amostra era suficiente, mas também que, com ela seria possível alcançar o objetivo do respectivo estudo.

No que se refere ao critério de exclusão, considerou-se participantes que: - estavam separados há mais de três anos; estavam fora do critério de idade (menores de 21 anos ou com mais de 40 anos);- sem filhos e; - residentes fora do estado da Bahia. Considerou-se ainda que, quando consultado, in loco, o participante aceitasse responder o instrumento completo.

\section{Instrumentos}

Os sujeitos responderam à Escala de Autoeficácia Parental: A autoeficácia parental seria avaliada utilizando o instrumento The Self-efficacy for Parenting Tasks Índex - Toddler Scale, desenvolvido por Coleman e Karraker (2003), utilizado especificamente, para sua avaliação em mães com filhos bebês. Esta escala avalia a autoeficácia de forma coerente com a teoria de Bandura, ou seja, utiliza itens que são percepções das mães em relação ao seu desempenho parental, em situações específicas.

Os 53 itens que constituem esta escala dividem-se por sete categorias:

1. disponibilidade emocional, "Quando o meu filho(a) precisa de mim, sou capaz de colocar de parte qualquer outra coisa para estar com ele";

2. responsividade empática, "Sou capaz de perceber quando o meu filho(a) começa a ficar angustiado";

3. protecção, "Oferecer um ambiente seguro e livre de perigos ao meu filho(a) é difícil para mim";

4. disciplina e estabelecimentos de limites, "Tenho dificuldade em fazer com que o meu filho(a) me ouça"; 
5. brincar, "Consigo sempre pensar em alguma coisa para brincar com o meu filho(a);

6. ensinar, "O meu filho(a) aprende mais através de mim do que qualquer outra pessoa da vida dele(a)";

7. cuidados práticos, "Sou capaz de oferecer ao meu filho(a) uma boa organização diária".

Cada item avalia-se por uma escala de Likert de seis pontos, em que as possibilidades de resposta oscilam entre "concordo totalmente" e "discordo totalmente". Esta escala foi traduzida por Correia (2008), para o contexto português, e manteve sua característica original de medida do construto. A autora citada pretendeu avaliar as percepções dos pais em relação ao seu desempenho parental, em situações específicas, revelando indicadores de consistência interna aceitável, os quais estiveram acima de 0,70 o Alpha de Cronbach.

Além desse instrumento, um questionário sociodemográfico foi inserido para coletar: idade, sexo, renda econômica, tempo de separação, quantidade de filhos e idade dos filhos.

\section{Procedimentos e aplicação do instrumento}

Colaboradores com experiência prévia na administração do instrumento foram responsáveis pela coleta dos dados in loco. É preciso destacar que antes da aplicação do questionário pretendido, o projeto que deu origem ao artigo seguiu todo o procedimento previsto na Resolução 466/2012 do Conselho Nacional de Saúde (CNS) e na Resolução 016/2000 do Conselho Federal de Psicologia brasileiro para as pesquisas com seres humanos e Associação Nacional de Pesquisa e Pós-Graduação em Psicologia (ANPEPP), 2000).

Após a submissão e aprovação do projeto, realizada pelo conselho de ética da plataforma brasil submetido ao conep sob o protocolo de pesquisa caae $\mathrm{n}^{\circ}$ 15089719.0.0000.5175, o instrumento da pesquisa foi aplicado aos pais e mães de forma individual, através de um formulário impresso apresentado aos mesmos.

Foi realizado um convite para participar da pesquisa e destinado um espaço físico com a presença do pesquisador responsável, coordenador do estudo. de acordo com a disponibilidade do tempo e interesse do participante que de forma voluntária, anônima e privada passava a responder ao questionário. foi solicitada uma autorização prévia dirigida aos mesmos, expressa no termo de compromisso livre e esclarecido - TCLE, no qual apresentavam-lhes os objetivos da referida pesquisa.

\section{Análise de dados}

Para a análise dos dados, utilizou-se o pacote estatístico SPSSWIN, versão 24.0, para tabular os dados e realizar as análises estatísticas descritivas (média, desvio padrão e mediana), correlação de Pearson, teste de $t$ de Student e alfa de Cronbach, e ANOVA One-way. Cálculos estes, para descrição da amostra e das respostas dos sujeitos nas escalas apresentadas a eles. E para avaliação de correlação tanto entre itens e constructo, quanto entre os próprios construtos e para diferenciar os níveis mais alto e mais baixo apresentados pelos sujeitos em cada item do instrumento e, por fim, o alfa, destinou-se à avaliação da consistência dos instrumentos, devido a especificidade do contexto amostral da pesquisa.

Para verificar a proposta do modelo teórico, tanto em seu conceito e fatoração quanto em sua qualidade psicométrica, realizou-se, no programa AMOS Grafics 22.0, a verificação dos indicadores estatísticos, através do cálculo de Modelagem de Equações Estruturais (MEE), para o qual, considerou-se tanto a adequação de ajuste subjetivo dos índices de modificação quanto das orientações empíricas (Faul, Erdfelder, Lang, \& Buchner, 2007). O uso desse programa estatístico se deve ao fato de que ele tem a função de apresentar, de forma mais robusta, indicadores psicométricos que visem à uma melhor construção da adaptação e acurácia da escala desenvolvida, bem como, permita desenhar um modelo teórico pretendido no estudo. Sendo um tipo de análise estatística mais criteriosa e rigorosa, testou-se o modelo teórico que se pretendia, considerando alguns índices que permitem avaliar a qualidade de ajuste do modelo proposto (Van De Vijver, \& Leung, 1997; Hair, Tatham, Anderson, \& Black, 2005): 
$\mathrm{O} \chi^{2}$ (qui-quadrado) testa a probabilidade do modelo teórico em se ajustar aos dados: quanto maior o valor do $\chi^{2}$ pior o ajustamento. Entretanto, apesar de pouco empregado na literatura, o mais comum a considerar foi sua razão em relação aos graus de liberdade ( $\chi^{2} /$ g.l.). Neste caso, valores até 3 indicam um ajustamento adequado; O Goodness-of-Fit Index (GFI) e o Adjusted Goodness-of-Fit Index (AGFI) são análogos ao $\mathrm{R}^{2}$ na regressão múltipla e, portanto, indicam a proporção de variância - covariância nos dados explicados pelo modelo.

Os valores desses indicadores variam de 0 a 1 , sendo que os valores na casa dos 0,80 e 0,90 , ou superiores, indicam um ajustamento satisfatório; A Root-Mean-Square Error of Approximation (RMSEA), com seu intervalo de confiança de 90\% (IC90\%), é considerado um indicador de "bondade" de ajuste, isto é, valores altos indicam um modelo não ajustado.

Assume-se como ideal que o RMSEA se situe entre 0,05 e 0,08, aceitando-se valores até 0,10; O Comparative Fit Index (CFI) - compara de forma geral o modelo estimado ao modelo nulo, considerando valores mais próximos de um como indicadores de ajustamento satisfatório.

Também, foi realizado tanto o cálculo de confiabilidade composta (CC) quanto da variância média extraída (VME); no primeiro indicador exige-se que o nível do escore seja acima de 0,70 , enquanto no segundo indicador é preciso um nível acima de 0,50 (Hair, Anderson, Tatham \& Black, 2005).

Com a coleta de dados finalizada, durante o período de novembro e dezembro de 2019, em que foram utilizados oito períodos, as respostas dos participantes foram inseridas na planilha do programa Excell e, em seguida, transferidas para pacote estatístico SPSS 24.0, no qual, foram realizadas as análises estatísticas.

\section{Resultados}

Numa primeira etapa de conferência dos resultados, buscou-se verificar se não teriam respostas duplicadas e/ou itens sem resposta e identificou-se que não existiu nenhuma resposta dos instrumentos administrados, com erro no preenchimento por parte dos respondentes.

Realizada essa avaliação inicial, verificou-se a qualidade e adequabilidade do 'n' amostral para a pesquisa. Para isso, avaliou-se a multicolinearidade entre as variáveis, as quais, revelaram correlações no intervalo dos parâmetros definidos por Tabachnick e Fidell (2001) [ $\mathrm{r} \leq 0,90$, variando de 0,21 a 0,75$]$; estes critérios, por sua vez, permite afirmar a não existência de variáveis com alta correlação, não interferindo na elaboração de modelos correlacionais com baixo erro de medida.

Também, foi avaliada a presença de outliers multivariados; através do teste de normalidade de Kolmogorov-Smirnov (KS), utilizada para avaliação com amostras superiores a 100 sujeitos (cf. Miot, 2017). Nesta análise, observou-se que amostra é normal apresentando os seguintes indicadores: $\mathrm{KS}=0,84, \mathrm{p}<0,37$.

Em relação à variância comum do método (VCM) (common method variance), pois, neste artigo, tanto as variáveis independentes (VI) quanto as dependentes (VD) mensuraram opiniões dos mesmos respondentes, condição a qual, poderia representar um problema referente à similaridade das repostas entre os respondentes na referida escala.

Com base na proposta empírica de Podsakoff, MacKenzie e Podsakoff (2003), que sugerem que, para a verificação do VCM, o teste de um fator de Harman nos dados coletados, deve atender um critério empírico, de um percentual menor do que 50\%, observou-se, ao gerar este cálculo, um único fator com auto-valor acima de 1,00, explicando uma variância abaixo do critério exigido pelos autores citados (18,98\% da covariância nas variáveis), implicando a não existência de um problema de variância comum do método.

Foi também, verificado a tendência de não-resposta. Considerando o procedimento indicado por Armstrong e Overton (1977), avaliaram-se a diferença entre os primeiros $(\mathrm{n} 1=30)$ e os últimos $(\mathrm{n} 2=30)$ participantes da pesquisa. Desta maneira, para a realização desta análise, utilizaram-se o teste de Levene e o teste $t$ de Student para avaliar, respectivamente, a igualdade das variâncias e dos meios entre os escores médios. 
As condições estatísticas revelaram que as diferenças não foram significativas $(\mathrm{p}<0,36)$ entre os escores médios dos construtos, bem como, o $t$ de Student foi $\leq 1,96$ (isto é, $t \leq 0,94$ ), podendo afirmar com tais resultados, que o viés de nãoresposta não é um problema significativo para as análises.

Considerando que a escala em questão, já foi validada para o contexto de língua portuguesa, mesmo que esta condição tenha sido com respondentes em Portugal (Correia, 2008), pretendeu-se atender ao objetivo principal desta pesquisa, referente à qualidade psicométrica de medida em contexto brasileiro.

O interesse em verificar essa etapa para essa pesquisa,deve-se às seguintes direções: 1 - trata-se de uma pesquisa pioneira, tanto em sua medida quanto ao objetivo pretendido em brasileiros, 2 - nas recentes buscas nos sites ${ }^{1}$ da produção científica brasileira na área psicologia social, psicologia do desenvolvimento, psicologia da família etc. não foram encontrados estudos quanto ao tema proposto e sua especificidade amostral relativa à avaliação psicológica.

Inicialmente, verificou-se o poder discriminativo dos itens, tendo como objetivo central apresentar maior especificidade na análise na avaliação da organização distributiva dos itens nas escalas administradas aos respondentes. Para a realização de tal análise, tomou-se como base de avaliação os pressupostos da Teoria Clássica dos Testes (TCT); tal perspectiva refere a necessidade de avaliar se os itens são capazes de discriminar as respostas das pessoas com magnitudes próximas, considerando os grupos com pontuações dos escores inferiores e superiores em relação ao construto medido (Formiga et al., 2016).

Para atender a condição hipotético-metodológica, previamente destacada com base na proposta teórica-empírica apresentada por Correia (2008), gerou-se uma pontuação total para esta escala e efetuou-se a sua mediana, a qual, organizou estatisticamente, um conjunto de escores considerados como grupo inferior e grupo superior de respostas. Estabeleceu que aqueles respondentes que apresentaram pontuação abaixo da mediana foram classificados como sendo do grupo inferior e para aqueles com pontuações acima da mediana, definidos como do grupo superior (Formiga et al., 2016).

Considerando-se os itens desta medida, foi realizado um teste t de Student para amostras independentes, a fim de comparar os grupos inferiores e superiores, relacionados à discriminação de cada item para os respondentes com magnitudes próximas estatisticamente significativas. Observou-se que todos os itens foram significativos (p-valor $<0,001$ ) e com um 't de Student' acima de 1,96, variando de $-2,95$ a -6,70, tendo os escores médios sempre maiores para grupo superior, isto é, para aqueles que têm o máximo concordante com o item.

Entretanto, pode-se afirmar que todos os itens desta medida para os respondentes, seja maior ou menor a pontuação do respectivo item na escala, permite apontar que eles compreenderam o conteúdo estabelecido por Correia (2008). Dessa forma, realizou-se em seguida a avaliação da representatividade de conteúdo relativo aos escores correlacionais itens-pontuação total para a escala. Este tipo de análise verifica a relação entre os itens e o construto (somatório total da medida), o qual, tem como base avaliar a representação conceitual comportamento-domínio (Pasquali, 2011).

Sistematicamente, através dessa análise estatística, busca-se verificar a relação teórica apresentada nos itens da escala associadas às situações especificadas neles e o quanto representam os aspectos esperados (Formiga et al., 2016). A partir do cálculo da correlação de Pearson (r), verificou-se a relação dos itens da escala com a pontuação total da mesma, condição a qual, espera-se que sejam significativos e tenham correlações acima de 0,50 . Observou-se que a correlação item-pontuação total, tanto foram positivas e significativas, quanto estiveram acima do esperado $(>0,50)$, variando de 0,52 a 0,68 .

A partir desses cálculos, é possível afirmar que os sujeitos da pesquisa foram capazes de representar cognitivamente o conteúdo e sentido expresso nos itens relacionados ao construto abordado neste artigo, pois, os respondentes pontuaram na forma que se esperava, quando relativo à discriminação dos itens $(\mathrm{t} \geq 1,96)$ e na representatividade de conteúdo $(\mathrm{r} \geq 0,50)$.

\footnotetext{
${ }^{1}$ (por exemplo, scielo.br, newpsi.bvs-psi.org.br, pepsic.bvsalud.org, www.periodicos.capes.gov.br).
} 
Ao aceitar essa condição, pode-se indicar maior segurança da medida em questão, especialmente, ao pretender utilizála na avaliação do fenômeno apresentado nesta pesquisa por meio dessa escala. Com isso, procurou-se na etapa seguinte, com base na proposta axiomática da estrutura fatorial da Escala de Autoeficácia Parental - EAEP de Correia (2008), verificar a análise e a estrutura fatorial, apontada pela autora. Para atender a esta condição limite, realizou-se uma análise de equação e modelagem estrutural do construto, para o qual, compararam-se o modelo com sete fatores, proposto por Correia (2008) (modelo oblíquo, com os fatores relacionados) ao modelo unifatorial (isto é, um modelo quanto pontuação total) e o modelo ortogonal (neste, as dimensões são independentes, isto é, não relacionadas).

Para verificar a estrutura fatorial da EAEP, deixa-se livre as covariâncias (phi, $\varphi$ ) entre os fatores, observando que os indicadores de qualidade de ajuste do modelo pretendido, estiveram próximas às recomendações apresentadas na literatura sobre este tipo de análise estatística (Perez-Gil, Moscoso, \& Rodriguez, 2000; Hair, Anderson, Tatham, \& Black, 2005; Sass, 2011; Geiser, Burns, \& Servera, 2014).

Os resultados obtidos nestas análises, expostos na Tabela 1, revelaram indicadores estatísticos que justificam a qualidade e consistência da estrutura fatorial pretendida; sendo assim, o modelo heptafatorial (isto é, de sete fatores) ajustado da EAEP é o mais adequado para sua avaliação em pais separados.

Tabela 1. Indicadores psicométricos da estrutura fatorial da EAEP.

\begin{tabular}{|c|c|c|c|c|c|c|c|c|c|}
\hline $\begin{array}{l}\text { Modelos } \\
\text { Fatoriais }\end{array}$ & $\chi^{2 / g l}$ & RMR & GFI & AGFI & CFI & TLI & $\begin{array}{c}\text { RMSEA } \\
\text { (intervalo) }\end{array}$ & CAIC & $\begin{array}{c}\text { ECVI } \\
\text { (intervalo) }\end{array}$ \\
\hline Unifatorial & 3,16 & 0,16 & 0,43 & 0,36 & 0,60 & 0,57 & $\begin{array}{c}0,10 \\
(0,10-0,11)\end{array}$ & 5020,18 & $\begin{array}{c}21,81 \\
(20,87- \\
22,80)\end{array}$ \\
\hline $\begin{array}{l}\text { Heptaforial } \\
\text { Ajustado } \\
\text { Ortogonal }\end{array}$ & 2,96 & 0,24 & 0,58 & 0,55 & 0,65 & 0,66 & $\begin{array}{c}0,10 \\
(0,09-0,10)\end{array}$ & 4362,94 & $\begin{array}{c}19,64 \\
(18,74- \\
20,56)\end{array}$ \\
\hline $\begin{array}{l}\text { Heptaforial } \\
\text { Ajustado } \\
\text { Oblíquo }\end{array}$ & 1,47 & 0,05 & 0,91 & 0,89 & 0,93 & 0,92 & $\begin{array}{c}0,05 \\
(0,04-0,05)\end{array}$ & 3130,52 & $\begin{array}{c}11,51 \\
(10,60- \\
11,74)\end{array}$ \\
\hline
\end{tabular}

Fonte: Autores.

Associados aos indicadores psicométricos destacados acima, consideraram-se também, o AIC (Akaike's Information Criterion), BIC (Bayes Information Criterion) e BCC (Browne-Cudeck Criterion), estes, por sua vez, complementam o CAIC (Consistent Akaike Information Criterion) e ECVI (Expected Cross-Validation Index), destinados à avaliação de adequação do modelo, teoricamente, estabelecido comparado a um outro ou outros modelos fatoriais (Marôco, Tecedeiro, Martins, \& Meireles, 2008).

No caso dos resultados explorados neste artigo, foi comparado o modelo heptafatorial ajustado com o unifatorial, a fim de verificar a estrutura fatorial proposta por Correia (2008). Sendo assim, observou-se que, no modelo ajustado com sete fatores o resultado foi o $\mathrm{AIC}=2219,27, \mathrm{BIC}=2918,52$ e $\mathrm{BCC}=2377,18$, enquanto o modelo unifatorial apresentou um AIC $=$ $4341,05, \mathrm{BIC}=4862,18$ e $\mathrm{BCC}=4458,73$.

Desta maneira, é destacável que os melhores indicadores estiveram para o modelo heptafatorial. Na literatura psicométrica, a respeito desses indicadores, quanto menor escore melhor a segurança do modelo fatorial, condição essa, que confirma a proposta da estrutura salientada por Correia (2008).

A partir dos indicadores apresentados na Tabela 2, destaca-se que todas as saturações (Lambdas, $\lambda$ ) estiveram no intervalo, estatísticamente, esperado $\mid 0$ - $1 \mid$, bem como, foram diferentes de zero $(t>1.96, p<.05)$, sendo assim, significativas. Com isso, revelando a não existência de problemas da estimação proposta na medida em questão, as quais, superior a zero e não ultrapassando um (1) (cf. tabela 2). 
Tais resultados corroboram a existência do modelo heptafatorial hipotetizado para mensurar a autoeficácia parental, organizada fatorialmente nas seguintes dimensões: Disponibilidade Emocional, Responsividade Empática, Proteção, Disciplina/Estabelecimento de Limites, Brincar, Ensinar e Cuidados Práticos, em pais separados.

Tabela 2. Estrutura Fatorial do EAEP em pais separados.

\begin{tabular}{|c|c|c|c|}
\hline $\begin{array}{c}\xi \\
\text { (Constructo) }\end{array}$ & $\begin{array}{c}\chi \\
\text { (Variáveis) } \\
\text { [itens] }\end{array}$ & $\begin{array}{c}\lambda \\
\text { (Escores } \\
\text { Associativos) }\end{array}$ & $\begin{array}{c}\mathrm{E} \\
(\text { erros})\end{array}$ \\
\hline \multirow{7}{*}{$\begin{array}{l}\text { Disponibilidade Emocional } \\
\text { (DE) }\end{array}$} & EAEP 1 & 0,54 & 0,39 \\
\hline & EAEP 2 & 0,68 & 0,47 \\
\hline & EAEP 3 & 0,64 & 0,41 \\
\hline & EAEP 4 & 0,65 & 0,43 \\
\hline & EAEP 5 & 0,66 & 0,44 \\
\hline & EAEP 6 & 0,66 & 0,43 \\
\hline & EAEP 7 & 0,60 & 0,39 \\
\hline \multirow{8}{*}{$\begin{array}{l}\text { Responsividade Empática } \\
\text { (RE) }\end{array}$} & EAEP 8 & 0,65 & 0,43 \\
\hline & EAEP 9 & 0,69 & 0,46 \\
\hline & EAEP 10 & 0,62 & 0,38 \\
\hline & EAEP 11 & 0,60 & 0,36 \\
\hline & EAEP 12 & 0,59 & 0,33 \\
\hline & EAEP 13 & 0,56 & 0,34 \\
\hline & EAEP 14 & 0,52 & 0,39 \\
\hline & EAEP 15 & 0,57 & 0,31 \\
\hline \multirow{7}{*}{$\begin{array}{l}\text { Proteção } \\
\text { (PROT) }\end{array}$} & EAEP 16 & 0,57 & 0,38 \\
\hline & EAEP 17 & 0,62 & 0,52 \\
\hline & EAEP 18 & 0,73 & 0,40 \\
\hline & EAEP 19 & 0,62 & 0,44 \\
\hline & EAEP 20 & 0,66 & 0,53 \\
\hline & EAEP 21 & 0,73 & 0,48 \\
\hline & EAEP 22 & 0,69 & 0,45 \\
\hline \multirow{7}{*}{$\begin{array}{l}\text { Disciplina/Estabelecimento de Limites } \\
\text { (DEL) }\end{array}$} & EAEP 23 & 0,76 & 0,55 \\
\hline & EAEP 24 & 0,64 & 0,41 \\
\hline & EAEP 25 & 0,71 & 0,50 \\
\hline & EAEP 26 & 0,79 & 0,65 \\
\hline & EAEP 27 & 0,80 & 0,64 \\
\hline & EAEP 28 & 0,81 & 0,66 \\
\hline & EAEP 29 & 0,70 & 0,48 \\
\hline \multirow{7}{*}{$\begin{array}{l}\text { Brincar } \\
\text { (BRIN) }\end{array}$} & EAEP 30 & 0,71 & 0,50 \\
\hline & EAEP 31 & 0,75 & 0,57 \\
\hline & EAEP 32 & 0,77 & 0,59 \\
\hline & EAEP 33 & 0,72 & 0,51 \\
\hline & EAEP 34 & 0,68 & 0,47 \\
\hline & EAEP 35 & 0,60 & 0,37 \\
\hline & EAEP 36 & 0,56 & 0,31 \\
\hline \multirow{9}{*}{$\begin{array}{l}\text { Ensinar } \\
\text { (ENS) }\end{array}$} & EAEP 37 & 0,62 & 0,41 \\
\hline & EAEP 38 & 0,74 & 0,59 \\
\hline & EAEP 39 & 0,80 & 0,63 \\
\hline & EAEP 40 & 0,79 & 0,53 \\
\hline & EAEP 41 & 0,86 & 0,65 \\
\hline & EAEP 42 & 0,88 & 0,73 \\
\hline & EAEP 43 & 0,85 & 0,72 \\
\hline & EAEP 44 & 0,83 & 0,69 \\
\hline & EAEP 45 & 0,77 & 0,59 \\
\hline
\end{tabular}


Research, Society and Development, v. 10, n. 4, e19610413649, 2021

(CC BY 4.0) | ISSN 2525-3409 | DOI: http://dx.doi.org/10.33448/rsd-v10i4.13649

\begin{tabular}{cccc}
\hline & EAEP 46 & 072 & 0,52 \\
& EAEP 47 & 0,76 & 0,54 \\
Cuidados Práticos & EAEP 48 & 0,77 & 0,58 \\
$(\mathrm{CP})$ & EAEP 49 & 0,78 & 0,60 \\
& EAEP 50 & 0,85 & 0,61 \\
& EAEP 51 & 0,86 & 0,62 \\
& EAEP 52 & 0,84 & 0,63 \\
\hline
\end{tabular}

Notas: $\lambda=$ Escores fatoriais da estrutura; $\varepsilon($ erros $)=$ Erros de medida da estrutura; $\mathrm{X}=$ variáveis (itens); $\xi=$ Construto psicológic o. $\mathrm{EAEP}=$ Escala de Autoeficácia Parental. Fonte: Autores.

Esse resultado se confirma quando se observa as estimativas de predição, que se originaram a partir da análise de regressão revelada para o modelo proposto, podendo identificar que as variáveis significativas e a razão critério, estiveram dentro do que é estatisticamente exigido (ver Tabela 3).

Tabela 3. Indicadores das estimativas preditivas da associação itens-fator da EAEP.

\begin{tabular}{|c|c|c|c|c|c|c|}
\hline Itens & Relação & Fatores & Estimativa & d.p. & $\begin{array}{c}\text { Razão } \\
\text { Critério }\end{array}$ & p-valor \\
\hline EAEP1 & $<---$ & $\mathrm{DE}$ & 1,00 & --- & ---- & --- \\
\hline EAEP2 & $<---$ & DE & 1,28 & 0,19 & 6,78 & 0,001 \\
\hline EAEP3 & $<--$ & $\mathrm{DE}$ & 1,12 & 0,17 & 6,52 & 0,001 \\
\hline EAEP4 & $<---$ & DE & 1,31 & 0,19 & 6,62 & 0,001 \\
\hline EAEP5 & $<---$ & $\mathrm{DE}$ & 1,29 & 0,19 & 6,67 & 0,001 \\
\hline EAEP6 & $<---$ & $\mathrm{DE}$ & 1,29 & 0,19 & 6,63 & 0,001 \\
\hline EAEP7 & $<--$ & $\mathrm{DE}$ & 1,17 & 0,18 & 6,42 & 0,001 \\
\hline EAEP15 & $<---$ & $\mathrm{RE}$ & 1,00 & --- & --- & --- \\
\hline EAEP14 & $<---$ & $\mathrm{RE}$ & 1,35 & 0,27 & 4,93 & 0,001 \\
\hline EAEP13 & $<--$ & $\mathrm{RE}$ & 1,54 & 0,30 & 5,04 & 0,001 \\
\hline EAEP12 & $<---$ & $\mathrm{RE}$ & 1,45 & 029 & 4,98 & 0,001 \\
\hline EAEP11 & $<---$ & $\mathrm{RE}$ & 1,44 & 0,84 & 5,07 & 0,001 \\
\hline EAEP10 & $<---$ & $\mathrm{RE}$ & 1,47 & 0,27 & 5,14 & 0,001 \\
\hline EAEP9 & $<---$ & $\mathrm{RE}$ & 1,88 & 0,35 & 5,36 & 0,001 \\
\hline EAEP8 & $<---$ & $\mathrm{RE}$ & 1,72 & 0,32 & 5,26 & 0,001 \\
\hline EAEP16 & $<---$ & PROT & 1,00 & --- & --- & --- \\
\hline EAEP17 & $<---$ & PROT & 1,18 & 0,17 & 6,69 & 0,001 \\
\hline EAEP18 & $<--$ & PROT & 1,23 & 0,16 & 7,35 & 0,001 \\
\hline EAEP19 & $<---$ & PROT & 1,04 & 0,15 & 6,80 & 0,001 \\
\hline EAEP20 & $<--$ & PROT & 1,25 & 0,18 & 6,98 & 0,001 \\
\hline EAEP21 & $<---$ & PROT & 1,35 & 0,18 & 7,39 & 0,001 \\
\hline EAEP22 & $<---$ & PROT & 1,17 & 0,16 & 7,17 & 0,001 \\
\hline EAEP23 & $<---$ & DEL & 1,00 & --- & --- & --- \\
\hline EAEP24 & $<---$ & DEL & 1,19 & 0,39 & 3,06 & 0,001 \\
\hline EAEP25 & $<--$ & DEL & 1,30 & 0,42 & 3,09 & 0,001 \\
\hline EAEP26 & $<---$ & DEL & 1,54 & 0,49 & 3,12 & 0,001 \\
\hline EAEP27 & $<---$ & DEL & 1,44 & 0,46 & 3,13 & 0,001 \\
\hline EAEP28 & $<--$ & DEL & 1,52 & 0,48 & 3,13 & 0,001 \\
\hline EAEP29 & $<---$ & DEL & 1,33 & 0,43 & 3,09 & 0,001 \\
\hline
\end{tabular}




\begin{tabular}{|c|c|c|c|c|c|c|}
\hline Itens & Relação & Fatores & Estimativa & d.p. & $\begin{array}{c}\text { Razão } \\
\text { Critério }\end{array}$ & $\mathrm{p}$-valor \\
\hline EAEP36 & $<---$ & BRIN & 1,00 & --- & --- & --- \\
\hline EAEP35 & $<---$ & BRIN & 1,03 & 0,15 & 6,59 & 0,001 \\
\hline EAEP34 & $<---$ & BRIN & 1,16 & 0,16 & 7,14 & 0,001 \\
\hline EAEP33 & $<---$ & BRIN & 1,25 & 0,17 & 7,35 & 0,001 \\
\hline EAEP32 & $<---$ & BRIN & 1,40 & 0,18 & 7,64 & 0,001 \\
\hline EAEP31 & $<---$ & BRIN & 1,40 & 0,18 & 7,55 & 0,001 \\
\hline EAEP30 & $<---$ & BRIN & 1,30 & 0,17 & 7,30 & 0,001 \\
\hline EAEP43 & $<---$ & ENSI & 1,00 & --- & --- & --- \\
\hline EAEP42 & $<---$ & ENSI & 1,00 & 0,06 & 16,35 & 0,001 \\
\hline EAEP41 & $<---$ & ENSI & 0,96 & 0,06 & 15,67 & 0,001 \\
\hline EAEP40 & $<---$ & ENSI & 0,90 & 0,06 & 13,76 & 0,001 \\
\hline EAEP39 & $<---$ & ENSI & 0,86 & 0,06 & 13,97 & 0,001 \\
\hline EAEP38 & $<---$ & ENSI & 0,82 & 0,06 & 12,40 & 0,001 \\
\hline EAEP37 & $<--$ & ENSI & 0,66 & 0,06 & 9,72 & 0,001 \\
\hline EAEP44 & $<---$ & ENSI & 0,90 & 0,06 & 14,91 & 0,001 \\
\hline EAEP45 & $<---$ & ENSI & 0,80 & 0,06 & 13,19 & 0,001 \\
\hline EAEP53 & $<---$ & CUPR & 1,00 & --- & --- & --- \\
\hline EAEP52 & $<---$ & CUPR & 1,08 & 0,08 & 13,17 & 0,001 \\
\hline EAEP51 & $<---$ & CUPR & 1,08 & 0,07 & 13,46 & 0,001 \\
\hline EAEP50 & $<--$ & CUPR & 1,06 & 0,07 & 13,34 & 0,001 \\
\hline EAEP49 & $<---$ & CUPR & 0,88 & 0,07 & 11,97 & 0,001 \\
\hline EAEP48 & $<---$ & CUPR & 0,85 & 0,07 & 11,86 & 0,001 \\
\hline EAEP47 & $<--$ & CUPR & 0,83 & 0,07 & 11,58 & 0,001 \\
\hline EAEP46 & $<---$ & CUPR & 0,77 & 0,07 & 10,89 & 0,001 \\
\hline
\end{tabular}

Nota: $\mathrm{DE}=$ Disponibilidade Emocional, RE $=$ Responsividade Empática, PROT $=$ Proteção, DEL $=$ Disciplina/Estabelecimento de Limites, $\mathrm{BRIN}=$ Brincar, ENS $=$ Ensinar e CP $=$ Cuidados Práticos. Fonte: Autores.

Considerando tais resultados, observou-se que a associação Phi $(\Phi)$ entre os fatores, revelou boa força associativa e também, na relação item-fator (variando de 0,33 a 0,84) (ver Tabela 4). É preciso destacar que, muitas dessas dimensões se associaram positivamente entre elas, mas, outras (por exemplo, Proteção-Ensino e Proteção-Cuidados práticos) estiveram associadas negativamente.

Tabela 4. Associações lambdas $(\lambda)$ entre as dimensões da EAEP.

\begin{tabular}{|c|c|c|c|c|c|c|c|}
\hline Variáveis/Fatores & $\mathrm{DE}$ & $\mathrm{RE}$ & PROT & DEL & BRIN & ENS & $\mathrm{CP}$ \\
\hline $\mathrm{DE}$ & --- & & & & & & \\
\hline $\mathrm{RE}$ & $0,76^{*}$ & --- & & & & & \\
\hline PROT & $0,39 *$ & $0,49 *$ & --- & & & & \\
\hline DEL & $0,37 *$ & $0,43^{*}$ & $0,55^{*}$ & --- & & & \\
\hline BRIN & $0,40^{*}$ & $0,50 *$ & $0,44^{*}$ & $0,38 *$ & --- & & \\
\hline ENS & $0,39 *$ & $0,40 *$ & $-0,37 *$ & $0,33^{*}$ & $0,38^{*}$ & --- & \\
\hline $\mathrm{CP}$ & $0,38^{*}$ & $0,43 *$ & $-0,34 *$ & $0,60 *$ & $0,38 *$ & $0,84^{*}$ & --- \\
\hline
\end{tabular}

Notas: $\lambda=$ Escores fatoriais da estrutura. $* \mathrm{p}<0,001 . \mathrm{DE}=$ Disponibilidade Emocional, $\mathrm{RE}=$ Responsividade Empática, PROT $=$ Proteção, $\mathrm{DEL}=$ Disciplina/Estabelecimento de Limites, BRIN = Brincar, ENS = Ensinar e CP = Cuidados Práticos. Fonte: Autores.

A partir desses resultados, pode-se destacar que a EAEP não apenas se estrutura numa fatorialidade oblíqua ajustada sob sete fatores, mas, também, que os seus fatores se associam entre si, significativamente. Considerando que o construto da EAEP neste artigo é confiável tanto em sua estrutura fatorial quanto em termos da definição deste e de seus fatores. 
Procurou-se avaliar qual dos fatores desta medida é mais prevalente. Assim, realizou-se um teste t para amostras pareadas entre as dimensões da EAEP, no qual, buscou avaliar as diferenças nas pontuações médias entre essas dimensões.

Na Tabela 5, pode-se observar que, com exceção do par 3 (DE-DEL), par 4 (DE-BRIN), par 15 (PROT-CP), par 16 (DEL-BRIN) e par 13 (PROT-BRIN), os quais, não foram significativos, sendo assim, não apresentaram diferenças entre seus escores; os demais pares tiveram significâncias entre eles. Chama-se atenção para a dimensão Ensino, a qual, revelou o maior escore médio entre os fatores, seguindo do segundo maior escore na dimensão Responsividade Empática.

Tabela 5. Escores médios pareados das dimensões da EAEP.

\begin{tabular}{|c|c|c|c|c|c|}
\hline Pares & Fatores & Média & d.p. & $\mathrm{T}$ & p-valor \\
\hline \multirow{2}{*}{ Pares 1} & $\mathrm{DE}$ & 29,88 & 4,24 & \multirow{2}{*}{$-25,17$} & \multirow{2}{*}{0,01} \\
\hline & $\mathrm{RE}$ & 36,66 & 4,44 & & \\
\hline \multirow{2}{*}{ Pares 2} & $\mathrm{DE}$ & 29,88 & 4,24 & \multirow{2}{*}{$-2,99$} & \multirow{2}{*}{0,01} \\
\hline & PROT & 30,98 & 4,80 & & \\
\hline \multirow{2}{*}{ Pares 3} & $\mathrm{DE}$ & 29,88 & 4,24 & \multirow{2}{*}{$-0,96$} & \multirow{2}{*}{0,23} \\
\hline & DEL & 30,29 & 5,69 & & \\
\hline \multirow{2}{*}{ Pares 4} & $\mathrm{DE}$ & 29,88 & 4,24 & \multirow{2}{*}{$-1,23$} & \multirow{2}{*}{0,22} \\
\hline & BRIN & 30,33 & 4,88 & & \\
\hline \multirow{2}{*}{ Pares 5} & $\mathrm{DE}$ & 29,88 & 4,24 & \multirow{2}{*}{$-13,48$} & \multirow{2}{*}{0,01} \\
\hline & ENS & 37,71 & 8,60 & & \\
\hline \multirow{2}{*}{ Pares 6} & $\mathrm{DE}$ & 29,88 & 4,24 & \multirow{2}{*}{$-2,95$} & \multirow{2}{*}{0,01} \\
\hline & $\mathrm{CP}$ & 31,66 & 8,09 & & \\
\hline \multirow{2}{*}{ Pares 7} & RE & 36,66 & 4,44 & \multirow{2}{*}{16,08} & \multirow{2}{*}{0,01} \\
\hline & PROT & 30,98 & 4,80 & & \\
\hline \multirow{2}{*}{ Pares 8} & RE & 36,66 & 4,44 & \multirow{2}{*}{15,32} & \multirow{2}{*}{0,01} \\
\hline & DEL & 30,29 & 5,69 & & \\
\hline \multirow{2}{*}{ Pares 9} & $\mathrm{RE}$ & 36,66 & 4,44 & 17.60 & 0.01 \\
\hline & BRIN & 30,33 & 4,88 & & \\
\hline Pares 10 & $\mathrm{RE}$ & 36,66 & 4,44 & 273 & 001 \\
\hline Pares iv & ENS & 37,71 & 8,60 & $-2,13$ & 0,01 \\
\hline Pares 11 & $\mathrm{RE}$ & 36,66 & 4,44 & 878 & $0 \Omega 1$ \\
\hline Pares 11 & $\mathrm{CP}$ & 31,66 & 8,09 & $8, / 8$ & 0,01 \\
\hline Pares 12 & PROT & 30,98 & 4,80 & 2.78 & 0.01 \\
\hline & DEL & 30,29 & 5,69 & & \\
\hline Dores 12 & PROT & 30,98 & 4,80 & 170 & 000 \\
\hline Pares 13 & BRIN & 30,33 & 4,88 & $1, / 0$ & 0,09 \\
\hline Pares 14 & PROT & 30,98 & 4,80 & 046 & 001 \\
\hline Pares 14 & ENS & 37,71 & 8,60 & $-9,40$ & 0,01 \\
\hline Pares 15 & PROT & 30,98 & 4,80 & -0.97 & 033 \\
\hline & $\mathrm{CP}$ & 31,66 & 8,09 & & \\
\hline Pares 16 & DEL & 30,29 & 5,69 & -012 & 090 \\
\hline & BRIN & 30,33 & 4,88 & & 0,90 \\
\hline Doro 17 & DEL & 30,29 & 5,69 & 1050 & مO \\
\hline tarts 17 & ENS & 37,71 & 8,60 & & \\
\hline Pares 18 & DEL & 30,29 & 5,69 & -295 & 0.01 \\
\hline Pares 18 & $\mathrm{CP}$ & 31,66 & 8,09 & $-2,95$ & 0,01 \\
\hline Pares 19 & BRIN & 30,33 & 4,88 & 1174 & 001 \\
\hline Fares 19 & ENS & 37,71 & 8,60 & $-11,14$ & 0,01 \\
\hline Pares 20 & BRIN & 30,33 & 4,88 & -208 & 001 \\
\hline Pares 20 & $\mathrm{CP}$ & 31,66 & 8,09 & $-2,08$ & 0,01 \\
\hline Pares 21 & ENS & 37,71 & 8,60 & 1603 & 001 \\
\hline Pares 21 & $\mathrm{CP}$ & 31,66 & 8,09 & 10,03 & 0,01 \\
\hline
\end{tabular}

Nota: $\mathrm{DE}=$ Disponibilidade Emocional, RE $=$ Responsividade Empática, $\mathrm{PROT}=$ Proteção, DEL $=$ Disciplina/Estabelecimento de Limites, BRIN $=$ Brincar, ENS $=$ Ensinar e CP $=$ Cuidados Práticos . 
Tendo sido comprovados as relações entre as variáveis, procurou-se avaliar a variabilidade das respostas dos sujeitos em função do sexo dos pais, da categoria amostral (pai e mãe), do sexo do filho, da idade do filho e do tempo de separação dos pais relacionado as dimensões da autoeficacia.

Desta maneira, a partir de um teste $t$ de Student para a variável sexo dos pais (pai e mãe) e as dimensões da EAEP, observou-se que para RE, ENS e CP as mães tiveram escores maiores do que os pais, enquanto nas dimensões, PROT, DE e DEL, esse resultado se inverte, os pais pontuaram mais alto do que as mães (ver Tabela 6).

Tabela 6. Diferenças entre os escores médios entre as dimensões da EAEP e pais.

\begin{tabular}{|c|c|c|c|c|c|}
\hline \multirow[b]{2}{*}{ Variáveis/Construto } & \multirow[t]{2}{*}{ Amostra } & \multirow[t]{2}{*}{ Média } & \multirow[t]{2}{*}{ d.p. } & \multicolumn{2}{|c|}{ Estatística } \\
\hline & & & & $\mathrm{T}$ & p-valor \\
\hline \multirow{2}{*}{$\mathrm{DE}$} & Mãe & 30,20 & 4,39 & \multirow[t]{2}{*}{1,15} & \multirow[t]{2}{*}{0,25} \\
\hline & Pai & 29,51 & 4,05 & & \\
\hline \multirow{2}{*}{$\mathrm{RE}$} & Mãe & 37,36 & 4,72 & \multirow[t]{2}{*}{2,41} & \multirow[t]{2}{*}{0,01} \\
\hline & Pai & 35,86 & 3,98 & & \\
\hline \multirow{2}{*}{ PROT } & Mãe & 30,04 & 4,91 & \multirow[t]{2}{*}{$-3,04$} & \multirow[t]{2}{*}{0,001} \\
\hline & Pai & 32,06 & 4,45 & & \\
\hline \multirow{2}{*}{ DEL } & Mãe & 29,47 & 5,96 & \multirow[t]{2}{*}{$-2,21$} & \multirow[t]{2}{*}{0,01} \\
\hline & Pai & 31,22 & 5,24 & & \\
\hline \multirow{2}{*}{ BRIN } & Mãe & 30,22 & 4,82 & \multirow[t]{2}{*}{$-0,34$} & \multirow[t]{2}{*}{0,73} \\
\hline & Pai & 30,46 & 4,98 & & \\
\hline \multirow{2}{*}{ ENS } & Mãe & 43,13 & 5,26 & \multirow[t]{2}{*}{12,95} & \multirow[t]{2}{*}{0,001} \\
\hline & Pai & 31,47 & 7,40 & & \\
\hline \multirow{2}{*}{$\mathrm{CP}$} & Mãe & 36,75 & 6,08 & \multirow[t]{2}{*}{12,61} & \multirow[t]{2}{*}{0,001} \\
\hline & Pai & 25,80 & 5,85 & & \\
\hline
\end{tabular}

Notas: $\mathrm{DE}=$ Disponibilidade Emocional, $\mathrm{RE}=$ Responsividade Empática, $\mathrm{PROT}=$ Proteção, DEL $=$ Disciplina/Estabelecimento de Limites, BRIN $=$ Brincar, ENS $=$ Ensinar e CP $=$ Cuidados Práticos .

No que se refere ao sexo do filho, apenas a dimensão de ENS $(\mathrm{t}=2,43$, $\mathrm{p}$-valor $=0,05)$ e $\mathrm{CP}(\mathrm{t}=-2,13$, $\mathrm{p}$-valor $=$ 0,05 ) foi significativa, revelando escores mais altos para filho do sexo feminino. Para avaliar as demais variáveis (sexo do filho, tempo de separação, idade do filho) efetuou-se uma Anova one-way.

No que se refere aos números dos filhos, nenhuma das dimensões revelou diferenças relacionado ao ter 1,2 ou 3 filhos. Em relação ao tempo de separação, os resultados foram significativos apenas para ENS $(\mathrm{F}=5,23, \mathrm{gl}=199$, p-valor, 0,01) e CP $(\mathrm{F}=5,95, \mathrm{gl}=199$, $\mathrm{p}$-valor, 0,01), tendo escores superiores para o período de 2 anos de separação, dos que variaram na amostra do estudo ente 1 a 3 anos.

\section{Discussão}

Com base nestes resultados, pode-se afirmar que a escala de autoeficácia parental desenvolvida por Correia (2008), no contexto português, em mães, foi corroborada o contexto brasileiro em pais (mãe e pai) separados. É possível destacar que a estrutura fatorial composta por 53 itens é distribuída em sete fatores e é confiável com uma amostra de pais em geral, bem como, na especificidade amostral de mãe e pai.

Nas amostras, os indicadores psicométricos corresponderam ao que é estatisticamente exigido na literatura estatística e psicométrica (Hair; Anderson, Tatham, \& Black, 2005; Marôco, Tecedeiro, Martins, \& Meireles, 2008; Pasquali, 2011). 
Com os indicadores psicométricos apresentando consistência, outro detalhe foi a associação itens-fator em relação à teoria e medida proposta por Correia (2008); condição que revelou associações lambdas $(\lambda)$ acima de 0,50 , bem como, uma interdependência $(\phi)$ entre os sete fatores da escala.

Com exceção dos fatores Ensino, Cuidados práticos e Proteção I que estiveram relacionados negativamente, os demais associaram-se de forma positiva. Assim, aquele sujeito que pontuar alto em um desses fatores (no resultado desta pesquisa), provavelmente, apresentará um alto escore no outro fator.

Chama-se atenção para a relação negativa entre os fatores destacados no parágrafo anterior (Ensinos, Cuidados Práticos e proteção), pois essa relação poderá ser compreendida através de uma análise do comportamento de pais e mães em relação à segurança dos filhos. O excesso da segurança faz com que os filhos sejam criados em bolhas, para que eles sejam poupados de todo o mal que acometeria o mundo (Millet, 2018).

Se já é difícil manter em devido equilíbrio o sentimento de amor e cuidado diante da super proteção em lares, nos quais os pais vivem juntos, imagine-se quando os pais vivem separados! Toda a dinâmica que envolve casais separados, já apresentado nesse artigo, colabora inquestionavelmente com o devir da criança. Mães e pais devido à situação de separação ou divórcio, quando sozinhos com a criança, acabam tirando da criança a chance de testar seus limites (errar para acertar depois), de ser curiosa, de saber lidar com problemas, de ter autonomia e se defender, fazendo com que o ensino para tais momentos seja comprometido (Zordan, 2010).

Dessa forma, quanto mais alto o escore da proteção, menos condições de ensinar aos filhos a mãe ou pai terá, fazendo com que eles se tornem pessoas frágeis. Algumas pesquisas demonstraram (Almeida, Peres, Garcia, \& Pellizzar, 2000; Zordan, 2010), que muitos filhos vivenciam estado de depressão, ansiedade e solidão em relação com uma educação super-protetiva. O excesso do cuidado pode impedir que os filhos deixem de assumir as tarefas do dia a dia, não permitindo que eles aprendam com a experiência pessoal, uma das fontes da percepção de autoeficácia.

O senso e o dever de proteger o filho, quando aproxima de uma obsessão por um "hiperfilho" (ou seja, perfeito e intocável) resulta em algo que denominou de hipocriança, um indivíduo mais frágil, inseguro e dependente, que carece de uma habilidade fundamental que é a autonomia (Millet, 2018).

A educação parece, portanto, estar do outro lado da proteção, com isso, a criança terá dificuldade em aprender por conta própria, pois o pai ou a mãe fará por ela ou irá poupá-la das dificuldades (Millet, 2018).

A importância dessa relação entre o Ensino e a Proteção, indica o mesmo que a Neurociências vem apresentando em seus estudos a respeito da função motora da criança, pois quando pais ao protegerem seus filhos, não permitem que eles caiam, ou rapidamente os ajudam a levantar, ou ainda executam as ações que eles deveriam fazer, resulta em atividades neuronais estacionadas, exatamente num período em que deveriam ser estimulados, ou seja, na primeira infância (Lent, 2010).

Com isso, eles impedem que os filhos se desenvolvam, atrasando ainda, as funções cognitivas. Assim, muitas vezes, a criança não consegue fazer algo que já deveria ser capaz (Lent, 2010; Millet, 2018). A proteção também pode explicar o fato de muitas crianças serem distraídas com cuidados básicos pessoais, por terem em casa alguém que faz o que elas deveriam fazer. A relação com o cuidado básico, pode ser resultado do estresse e cansaço mental e físico ao carregar responsabilidade e culpa, submersas no medo de perderem os filhos (Millet, 2018).

Essa superproteção impede que a criança entre em contato com emoções, como raiva, angústia e decepção, que serão fundamentais para seu desempenho psíquico (Almeida, Peres, Garcia, \& Pellizzar, 2000; Zordan, 2010; Lent, 2010; Millet, 2018). Em termos gerais, o modelo estrutural comprovado garante a medida do construto que avalia as sete dimensões da autoeficácia em pais separados, referindo-se a crença desenvolvida pelos pais de que eles são capazes de produzir os resultados que pretendem, considerando um grande elemento teórico da preditividade de uma parentalidade positiva (Correia, 2008; 
Tristão, Neiva, Barnes, \& Adamson-Macedo, 2015); dimensões essas: - disponibilidade emocional; - responsividade empática; - proteção; - disciplina/ estabelecimento de limites, - brincar; - ensinar e; - cuidados práticos.

Outra condição fornecida por essa escala, caso se pretenda administrá-la apenas em pai ou em mãe (separadamente), que vive o processo de separação, também, será possível, pois, na análise confirmatória, os indicadores de consistência interna revelaram confiabilidade para esse tipo de avaliação.

A discussão exposta acima pode ser observada nos resultados da Tabela 6 (vide p. 24), pois houve diferença entre os escores do pai e da mãe na autoeficácia, situação que permite que o profissional das áreas da psicologia, da educação ou até da assistência social, utilize as informações contidas nos escores da escala para oferecer uma intervenção ou orientação na construção do afeto e comportamento mais seguro para o binômio pai-filho(a) e mãe-filho(a) (Tristão, Neiva, Barnes, \& Adamson-Macedo, 2015).

No que se refere à avaliação entre os escores médios, na análise da amostra pareada entre as sete dimensões da autoeficácia, destaca-se a existência de uma hierarquia nesses escores, observando que a dimensão Ensinar da autoeficácia foi a que revelou maior escore, seguido de Responsividade Empática e Cuidados Práticos.

Chama-se atenção que as dimensões que representam algo mais expressivo e que requer o desenvolvimento de sentimentos e pensamentos, foram as que apresentaram maiores escores. Condição esta que reflete uma necessidade de maior atenção dos pais para o desenvolvimento de habilidades sociais na relação com seus filhos.

\section{Considerações Finais}

A importância de se avaliar este construto se deve ao fato não apenas de não existir no Brasil uma medida com a direção teórica que a pretensa escala propõe (Correia, 2008); mas devido à falta de instrumentos avaliativos para pais separados. Considerar uma medida de autoeficácia para uma amostra com esta categoria, é contribuir para que pai e mãe aprendam e desenvolvam sua dimensão sócio-cognitiva de forma mais consciente em relação às experiências de vida de seus filhos (Iraurgi Castillo, Muñoz Eguilet, Sanz Vázquez, \& Martínez-Pampliega, 2010).

A reflexão destacada acima tem sua direção a partir dos resultados, expresso na Tabela 6 (vide p. 24), já que nela é possível observar que as mães pontuaram mais alto em dimensões referentes à estruturação e funcionalidade emocional e de expressividade $(\mathrm{RE}=$ Responsividade Empática, $\mathrm{ENS}=$ Ensinar e $\mathrm{CP}=$ Cuidados Práticos), enquanto os pais, apresentaram escores maiores nas dimensões mais instrumentais (PROT $=$ Proteção e DEL $=$ Disciplina/Estabelecimento de Limites). Tais resultados poderão ser compreendidos em termos da necessidade de assimilar uma resolução de problemas mais focada no outro do que em si, especialmente, frente à condição de disposição ao perdão, validação de emoções e comportamentos saudáveis (Rique \& Camino, 2010; Rique, Camino, Formiga, Medeiros, \& Luna, 2010).

Considerando os achados nesta pesquisa, não somente assume-se o modelo heptafatorial para mensurar a autoeficácia parental, corroborando a proposta de Correia (2008), como salienta-se a importância deste construto quando se pretender avaliar a qualidade da estrutura e função psíquica emocional de pais (pai e mãe) separados, especialmente, quando essa situação interferir na qualidade de vida física e afetiva no binômio pai-filho e mãe-filho.

Espera-se que os objetivos da verificação da organização fatorial da medida de autoeficácia em pais separados, a partir de indicadores estatísticos mais robustos tenham sido cumpridos, condição que se mantem convergente com as orientações indicadas por Correia (2008), na avaliação desse construto.

Sugere-se em relação a futuros estudos, uma avaliação dos construtos envolvendo não apenas os pais separados, mas, compará-los com uma amostra de pais não-separados, pais com segundo casamento (com foco no estado civil) ou relacionamento estável, bem como, relacionamento homoafetivo. 


\section{Referências}

Albanese, A. M., Russo, G. R., \& Geller, P. A. (2019). The role of parental self-efficacy in parent and child well-being: A systematic review of associated outcomes. Child Care Health Dev. 2019; 45: 333- 363. https://doi.org/10.1111/cch.12661

Almeida, C. G. de, et al. (2000). Pais separados e filhos: análise funcional das dificuldades de relacionamento. Estudos de Psicologia, 17(1), 3143. https://doi.org/10.1590/S0103-166X2000000100003

Armstrong, J. S., \& Overton, T. S. (1977). Estimating nonresponse bias in mail surveys. http://repository.upenn.edu/marketing_papers/17.

Bandura, A. (1989). Regulation of cognitive processes through perceived self-efficacy. Developmental Psychology, 25, 729-735.

Bandura, A. (1997). Self-efficacy: the exercise of control. Editora: Worth Publishers.

Bandura, A., Azzi, R. G., \& Polydoro, S. (2008). Teoria social cognitiva: conceitos básicos. Editora Artmed.

Baptista, Makilim Nunes, Alves, Gisele Aparecida da Silva, \& Santos, Thelma Margarida de Moraes dos. (2008). Suporte familiar, auto-eficácia e lócus de controle evidências de validade entre os construtos. Psicologia: Ciência e Profissão, 28(2), 260-271. https://doi.org/10.1590/S1414-98932008000200004

Barros, M., \& Batista-dos-Santos, A. C. (2010). Por dentro da autoeficácia: um estudo sobre seus fundamentos teóricos, suas fontes e conceitos correlatos. Revista Espaço Acadêmico, 10(112), 1-9. http://www.periodicos.uem.br/ojs/index.php/EspacoAcademico/article/view/10818

Benatov, J. (2019). Parents' feelings, coping strategies and sense of parental self-efficacy when dealing with children's victimization experiences. Frontiers in psychiatry, 10, 700. https://doi.org/10.3389/fpsyt.2019.00700

Brites, R., \& Nunes, O. (2015, fevereiro). Uma nova escala de autoeficácia parental: estudos sobre validação. Actas do VII simpósio nacional de investigação em psicología, inho, Portugal, 4 a 6 . https://www.researchgate.net/publication/264883381

Coleman, P. K., \& Karraker, K. H. (2003). Maternal self-efficacy beliefs, competence in parenting, and toddlers' behavior and developmental status. Infant Mental Health Journal, 24, 126-148.

Correia, C. S. L. (2008). O papel do apoio social na percepção de auto-eficáciaa parental de mães separadas, Portugal: Editora Universidade de Lisboa. http://sibul.reitoria.ul.pt/F/?func=itemglobal\&doc_library=ULB01\&type=03\&doc_number=000549534 http://hdl.handle.net/10451/768

Faul, F.; Erdfelder, E.; Lang, A.; \& Buchner, A. G. (2007). G*Power 3: A flexible statistical power analysis program for the social, behavioral, and biomedical sciences. Behavior Research Methods Instruments \& Computers. 39. 175-191.

Féres-Carneiro, T. (2003). Separação: o doloroso processo de dissolução da conjugalidade. Estudos de Psicologia, 8(3), $367-374$.

Formiga, N. S. et al. (2016). Evidência empírica de uma medida da anomia organizacional em trabalhadores brasileiros. Revista de Psicologia da UCV, 18 (1), $43-59$.

Frischknecht G. (2018). Avaliação da autoconfiança esportiva em atletas. Tese (Doutorado em Psicologia). Universidade Federal de Santa Catarina, UFSC.

Gouvea, M. C. S. (2003). Infância, sociedade e cultura. In Carvalho, A; Salles, F; e Guimarães, M. Desenvolvimento e aprendizagem. Editora UFMG; ProexUFMG.

Geiser, C., Burns, G. L., \& Servera, M. (2014). Testing for measurement invariance and latent mean differences across methods: interesting incremental information from multitrait-multimethod studies. Frontiers in psychology, 5, 1216. https://doi.org/10.3389/fpsyg.2014.01216

Hair, J. F., Anderson, R. E., Tatham, R. L., \& Black, W. (2005). Análise Multivariada de dados. Bookman.

Kabiyea, F., \& Manor-Binyamini, I. (2019). The relationship between stress and stigma, somatization and parental self-efficacy among fathers of adolescents with developmental disabilities in the Bedouin community in Israel. Research in developmental disabilities, 90, 31-40. doi.org/10.1016/j.ridd.2019.04.004

IBEDFAM (2018). Em 33 anos, divórcios aumentam 269\%, enquanto a população cresceu apenas 70\%. http://ibdfam.org.br/noticias/na-midia/16311/

Iraurgi Castillo, I., et al. (2010). Conflicto Marital y Adaptación de los Hijos: Propuesta de un Modelo Sistémico. Interamerican Journal of Psychology, 44(3),422-431. https://www.redalyc.org/articulo.oa?id=284/28420658003

Jablonski, B. (1991). Até que a vida nos separe: a crise do casamento contemporâneo. Agir.

Kaslow, F. W., \& Schwartz, L. (1995). As dinâmicas do Divórcio. Editoria PSI.

Kim, J., \& Ciccetti, D. (2003). Social self-efficacy and behaviour problems in maltreated and nonmaltreated children. Journal of Clinical Child and Adolescent Psychology, 32(1), 106-117.

Kyrillos, M. H. M. (2016). Motivos para a prática esportiva e o senso de autoeficácia em atletas. Dissertação (Mestrado em Educação Física). Universidade Federal de Sergipe, UFSE.

Lent, R. (2010). Cem bilhões de neurônios - conceitos fundamentais de neurociências. Editora Atheneu.

Lent, R., \& Brown, S. D. (2006). On conceptualizing and assessing social cognitive constructs in career research: A measurement guide. Journal of Career Assessment, 14(1), 12-35. 
Machado, T. do A., et al. Autoeficácia esportiva: uma revisão integrativa dos instrumentos de medida. Rev. educ. fis. UEM. 25(2): 323-333. http://www.scielo.br/scielo.php?script=sci_arttext\&pid=S1983-30832014000200323\&lng=en. https://doi.org/10.4025/reveducfis.v25i2.21685.

Maldonado, M.T. (1987). Casamento: término e reconstrução. Vozes.

Marcondes, M. V., Trierweiler, M., \& Cruz, R. M. (2006). Sentimentos predominantes após o término de um relacionamento amoroso: Predominant feelings after the end of a love relationship. Psicologia: ciência e profissão, 26(1), 94-105. http://pepsic.bvsalud.org/scielo.php?script=sci_arttext\&pid=S1414$98932006000100009 \& \operatorname{lng}=$ pt\&tlng=pt.

Maroco, J., \& Tecedeiro, M. (2008). Inventário de burnout de Maslach para estudantes portugueses. Psicologia, Saúde \& Doenças, $10(2), 227-235$. http://www.scielo.mec.pt/scielo.php?script=sci_arttext\&pid=S1645-00862009000200007\&lng=pt\&tlng=pt.

Meneses, P. P. M., \& Abbad, G. S. (2010). Construção e validação de um instrumento para avaliar auto-eficácia em situações de treinamento, desenvolvimento e educação de pessoas. Psicologia: Reflexão e Crítica, 23(1), 121-130. https://doi.org/10.1590/S0102-79722010000100015

Meunier, J., \& Roskam, I. (2009). Self-efficacy beliefs amongst parents of young children: Validation of a selfreport measure. Journal of Child \& Family Studies, 18, 495-511.

Millet, E. (2018). Hiperniños hijos perfectos o hipohijos? Editora Atual.

Murgo, C. L. L. F., \& Soares Sena, B. (2019). A ação pedagógica e a autoeficácia docente no ensino superior. EccoS - Revista Científica, O(48), 255-272. https://doi.org/10.5585/eccos.n48.8058

Nunes, M. F. O. (2008). Funcionamento e desenvolvimento das crenças de auto-eficácia: uma revisão. Revista Brasileira de Orientação Profissional, 9(1), 2942. http://pepsic.bvsalud.org/scielo.php?script=sci_arttext\&pid=S1679-33902008000100004\&lng=pt\&tlng=pt.

Oliveira, A. K. C. (2016). Autoconceito, autoeficácia e parentalidade: Crianças com deficiência física, com desenvolvimento típico e seus familiares. Tese (Doutorado). Universidade Federal de São Carlos.

Pajares, F. (2002).Current directions in selfefficacy research.Advances in motivation and achievement (10) 149. Greenwich, CT: JAI Press.

Pasquali L. (2011). Psicometria: Teoria dos testes na psicologia e na educação. (4a ed.), Vozes.

Pérez-Gil, J. A., Moscoso, S. C., \& Rodríguez, R. M. (2000). Validez de constructo: El uso de análisis factorial exploratorio-confirmatorio para obtener evidencias de validez. Psicothema, 12(2), 442-446. http://www.psicothema.com/pdf/601.pdf

Podsakoff, P. M., MacKenzie, S. B., Lee, J-Y, \& Podsakoff, N. P. (2003). Common method biases in behavioral research: a critical review of the literature and recommended remedies. Journal of Applied Psychology, 88(5): 879-903. 10.1037/0021-9010.88.5.879.

Rodriguez-Villamizar, L. A., \& Amaya-Castellanos, C. (2019). Estilos de crianza, autoeficacia parental y problemas conductuales infantiles en tres municipios de Santander. Revista de la Universidad Industrial de Santander. Salud, 51(3), 228-238. https://dx.doi.org/10.18273/revsal.v51n3-2019006

Rique, J., \& Camino, C. P. S. (2010). O perdão interpessoal em relação a variáveis psicossociais e demográficas. Psicologia: Reflexão e Crítica, 23(3), 525532. https://doi.org/10.1590/S0102-79722010000300013

Rique, J., et al. (2010). Consideração Empática e Tomada de Perspectiva para o Perdão Interpessoal. Interamerican Journal of Psychology, 44(3),515-522. https://www.redalyc.org/articulo.oa?id=284/28420658014

Salonen, A. H., Kaunonen, M., Astedt-Kurki, P., Jarvenpaa, A. L., Isoaho, H., \& Tarkka, M. T. (2009). Parenting self-efficacy after childbirth. Journal of Advanced Nursing, 65(11), 2324-2336.

Salvetti, M. G. (2004). Crença de auto-eficácia e validação da "Chronic Pain Self-Efficacy Scale". Dissertação de Mestrado não-publicada, Universidade de São Paulo, São Paulo.

Sass, D. A. (2011). Testing measurement invariance and comparing latent factor means within a confirmatory factor analysis framework. Journal of Psychoeducational Assessment, 29(4), 347-363. https://doi.org/10.1177/0734282911406661

Schabbel, C. (2005). Relações familiares na separação conjugal: contribuições da mediação. Psicologia: teoria $e$ prática, 7(1), 13-20. http://pepsic.bvsalud.org/scielo.php?script=sci_arttext\&pid=S1516-36872005000100002\&lng=pt\&tlng=pt.

Selau, F. F., et al. (2019). Self-efficacy sources and experimental physics activities: an exploratory study. Revista Brasileira de Ensino de Física, 41(2), e20180188. 08, 2018.https://dx.doi.org/10.1590/1806-9126-rbef-2018-0188

Silva, A. M. B. da, L., et al. (2015). Escala de Autoeficácia para Bailarinos (AEBAI): construção e evidências de validade. Avaliação Psicológica, 14(1), 8388. http://pepsic.bvsalud.org/scielo.php?script=sci_arttext\&pid=S1677-04712015000100010\&lng=pt\&tlng=pt.

Teyber, E., \& Hoffman,C. D. (1987). Missing Fathers. Psychology Today.(apr).

Tristão, R. M., Neiva, E. R., Barnes, C. R., \& Adamson-Macedo, E. (2015). Validação da escala percepção de autoeficácia da parentalidade materna em amostra brasileira. Journal of Human Growth and Development, 25(3), 277-286. https://dx.doi.org/10.7322/jhgd.96759

Van Dijk, S., Veenstra, M. S., Bouman, R., Peekel, J., Veenstra, D. H., van Dalen, P. J., van Asselt, A., Boshuisen, M. L., van Alphen, S., van den Brink, R., \& Oude Voshaar, R. C. (2019). Group schema-focused therapy enriched with psychomotor therapy versus treatment as usual for older adults with cluster B and/or C personality disorders: a randomized trial. BMC psychiatry, 19(1), 26. https://doi.org/10.1186/s12888-018-2004-4

Vieira, D., Soares, A. M., \& Polydoro, S. A. J. (2006). Escala de auto-eficácia na transição para o mundo do trabalho (AETT): Um estudo de validação para a realidade brasileira. In C. Machado, L. Almeida, M. A. Guisande, M. Gonçalves, \& V. Ramalho (Eds.), Conferência internacional de avaliação psicológica: 
Research, Society and Development, v. 10, n. 4, e19610413649, 2021

(CC BY 4.0) | ISSN 2525-3409 | DOI: http://dx.doi.org/10.33448/rsd-v10i4.13649

Formas e contexto (pp. 293-299). Psiquilíbrios.

Zordan, E. P. (2010). A separação conjugal na contemporaneidade: motivos circunstâncias e contextos. (Tese de Doutorado. Curso de Pós-Graduação em

Psicologia, Pontifícia Universidade Católica do Rio Grande do Sul, Porto Alegre, RS). 